\title{
Reasons and Patterns of Permanent Teeth Loss among Patients attending a Dental College in Kathmandu
}

\author{
Dr. Anju Khapung, ${ }^{1}$ Dr. G. Nagaraja Rao, ${ }^{2}$ Dr. Sujita Shrestha ${ }^{2}$ \\ ${ }^{1}$ Department of Community Dentistry, College of Dental Sciences, Nepal Medical College, Kathmandu, Nepal; \\ ${ }^{2}$ Department of Community Dentistry, Kantipur Dental College, Kathmandu, Nepal.
}

\begin{abstract}
Introduction: According to World Health Organization, oral health means the retention throughout life of a functional, aesthetic and natural dentition of not less than 20 teeth and not requiring a prosthesis. The major reasons for tooth loss are dental caries and periodontal disease. Proper understanding of reasons for tooth loss helps to improve oral health.

Objective: To identify the reasons and patterns of permanent teeth loss among patients attending Kantipur Dental College.

Methods: A cross-sectional study was carried out among 403 patients aged 18 years and above attending Kantipur Dental College, Kathmandu by convenience sampling method. Data was collected through structured questionnaire and clinical examination and was analysed using SPSS version 20.

Results: A total of 403 patients were examined of which 38\% had tooth loss. Mean number of tooth loss was 2.99+3.44. Statistically significant difference was found in mean tooth loss between age groups and levels of education (P value $<0.001$ ). Dental caries was the most common reason of tooth loss followed by periodontal disease. Most common reason for not saving the tooth was "tooth cannot be saved" (65.1\%). Mandibular molars accounted for majority of tooth loss followed by maxillary molars.

Conclusion: The results of the present study show that dental caries was the major cause of tooth loss irrespective of the age group. It points out the need to carry out oral health awareness and other preventive programs both at school and community levels.

Keywords: Dental caries; periodontal disease; tooth loss.
\end{abstract}

\section{INTRODUCTION}

Oral health is the retention throughout life of a functional, aesthetic and natural dentition of not less than 20 teeth and not requiring a prosthesis. ${ }^{1}$ Teeth play a major role in chewing, smiling and speaking. ${ }^{2}$ Teeth retention is also essential for social, functional, psychological and economical reasons. ${ }^{3}$ So it is important to retain permanent teeth as long as possible.

Various reasons for tooth loss include dental caries and its sequel, advanced periodontal disease, orthodontic reasons, impacted teeth, failed dental treatment, prosthetic indications and other reasons. ${ }^{4}$ So tooth loss also shows the patterns and prevalence of dental disease in a given population to some extent. ${ }^{5}$ In some cases, tooth loss occurs due to patient's preference for tooth extraction over restorative procedures

\section{Correspondence:}

Dr. Anju Khapung

Department of Community Dentistry, College of Dental Sciences, Nepal Medical College, Kathmandu, Nepal.

email: khapunganju@gmail.com

\section{Citation}

Khapung A, Rao GN, Shrestha S. Reasons and Patterns of Permanent Teeth Loss among Patients attending a Dental College. J Nepal Soc Perio Oral Implantol. 2020;4(7):10-3. because of need for acute treatment ${ }^{6}$ and poor socioeconomic conditions. ${ }^{7}$ Factors like age, gender and dental visits also affect the distribution of tooth loss. ${ }^{8}$

As tooth loss affects dietary practices and quality of life, it is essential to understand the reasons for teeth loss for the improvement of oral health. ${ }^{9}$ Tooth mortality data helps in evaluating whether dental care and preventive oral health programs are adequate or not. ${ }^{10}$ It also gives an insight into oral hygiene levels and dental health awareness among the people. ${ }^{11}$ Limited studies regarding the reasons and patterns of tooth loss have been done in the context of Nepal. So, this study aims to identify the reasons and patterns of permanent teeth loss among patients attending a dental hospital in Kathmandu.

\section{METHODS}

A cross-sectional study was carried out among 403 patients attending Department of Oral Medicine and Radiology, Kantipur Dental College during June, 2017. Minimum sample size was calculated by: $\mathrm{n}=\mathrm{N} /\left(1+\mathrm{Ne}^{2}\right)$.

Here $\mathrm{n}$ = sample size; $\mathrm{N}$ = population size (average number of patients attending the dental OPD per month as calculated from the dental OPD Register for the last six months) $=2874$; e $=$ margin of error (0.05). Thus, minimum sample 
size $=351$. By the end of data collection period, the total sample obtained by convenience sampling method was 403 .

All the participants less than 18 years and those not willing to participate were excluded from the study. Ethical approval was taken from Institutional Review Committee (IRC) of Kantipur Dental College. Written informed consent was taken from all the study participants. Data collection was done by a single investigator. A proforma was used that consisted of two parts, the first part included demographic details, reasons for tooth loss and reasons for not saving teeth. The second part included clinical examination for missing teeth by using mouth mirror and explorer. Third molars and tooth unerupted or congenitally missing were not counted as missing. Only permanent dentition was included.

Data concerning the missing teeth was collected and classified using the modified criteria set by Aderinokun. ${ }^{12}$ Dental caries was the reason whenever the primary cause of extraction was associated with caries, root remnant, failed endodontics, periapical abscess or fracture of tooth weakened by caries or endodontics. Tooth loss was considered to be due to periodontal disease when reason for extraction was pronounced periodontal breakdown, loose suppurating tooth or when periodontally involved tooth was removed before prosthetic therapy. The reason was considered as trauma when non-carious associated trauma to tooth was the reason for its removal and orthodontics when a tooth was removed during orthodontic treatment. The reason others included other reasons for tooth loss.

Data was entered in EpiData version 3.1. Data analysis was done using Statistical Package for Social Sciences (SPSS version 20). Descriptive and inferential statistics were used. Mann-Whitney U test was used to find the difference in number of missing teeth between the two age groups and between different genders. Kruskal-Wallis test was used to find the difference in number of missing teeth among different levels of education. $\mathrm{P}$ value $<0.05$ was considered as statistically significant.

\section{RESULTS}

Socio-demographic characteristics: A total of 403 patients were examined of which 152 (38\%) had tooth loss. Out of the total patients with tooth loss, 94 (61.9\%) were females and 58 (38.1\%) were males. The age of the patients ranged from 18-95 years with the mean age 45.14 years. Among the total study participants, 49 (32.3\%) had completed primary level of education and only 6 (3.9\%) had completed master's degree.

Pattern of tooth loss: Total number of tooth loss was 460. In the maxillary arch, the number of tooth loss was 206 (44.8\%) and it was 254 (55.2\%) in the mandibular arch. The mean tooth loss was 2.99+3.44. Mandibular 1st molars (19.8\%) accounted for majority of tooth loss followed by maxillary 1st molars (13.7\%) (Figures 1 and 2). More number of tooth loss was found in left side (243) than in right side (217).

Socio-demographic characteristics and association with tooth loss: Statistically significant difference was found in tooth loss among the study participants 30 years and older compared to those less than 30 years (P value $<0.001$ ). Tooth loss was observed to be more common in females than males but the difference was not statistically significant (P value $=0.392$ ). Tooth loss decreased as the education level of the patient increased and this difference was found to be statistically significant (P value $<0.001$, Table 1 ).

Reasons of tooth loss: Majority of the tooth lost were mandibular molars (84), mandibular central incisors (30), maxillary 1st premolars (4) and maxillary central incisors (15) due to reasons of dental caries, periodontal disease, orthodontic treatment and trauma respectively. Molars of both maxilla and mandible (72.3\%) were lost more than the remaining teeth due to dental caries. More numbers of anterior teeth (65) were lost than posterior (62) and more

Table 1: Tooth loss and its association with socio-demographic variables.

\begin{tabular}{|c|c|c|c|c|c|c|c|}
\hline & \multirow{2}{*}{ Variable } & \multirow{2}{*}{ n (\%) } & \multirow{2}{*}{$\begin{array}{l}\text { Median number } \\
\text { of missing teeth }\end{array}$} & \multicolumn{2}{|c|}{ Inter quartile Range } & \multirow{2}{*}{$\begin{array}{l}\text { Mean } \\
\text { Rank }\end{array}$} & \multirow{2}{*}{$P$ value } \\
\hline & & & & P25 & P75 & & \\
\hline \multirow{2}{*}{ Age (years) } & $<30$ & $30(19.7)$ & 1 & 1 & 2 & 51.23 & \multirow{2}{*}{$<0.001$} \\
\hline & $\geq 30$ & $122(80.3)$ & 2 & 1 & 4 & 82.71 & \\
\hline \multirow{2}{*}{ Gender } & Male & $57(37.5)$ & 1 & 1 & 4 & 74.98 & \multirow{2}{*}{0.392} \\
\hline & Female & $95(62.5)$ & 2 & 1 & 3 & 77.41 & \\
\hline \multirow{6}{*}{ Education } & Illiterate & $35(23)$ & 3 & 2 & 6 & 108.5 & \multirow{6}{*}{$<0.001$} \\
\hline & Primary school & $16(10.5)$ & 1.5 & 1 & 3 & 76.5 & \\
\hline & Secondary school & $49(32.3)$ & 2 & 1 & 2.5 & 73.99 & \\
\hline & High school & $27(17.8)$ & 1 & 1 & 2 & 56.69 & \\
\hline & Bachelor's degree & $19(12.5)$ & 1 & 1 & 2 & 60.89 & \\
\hline & Master's degree & $6(3.9)$ & 1 & 1 & 1.5 & 48.92 & \\
\hline
\end{tabular}




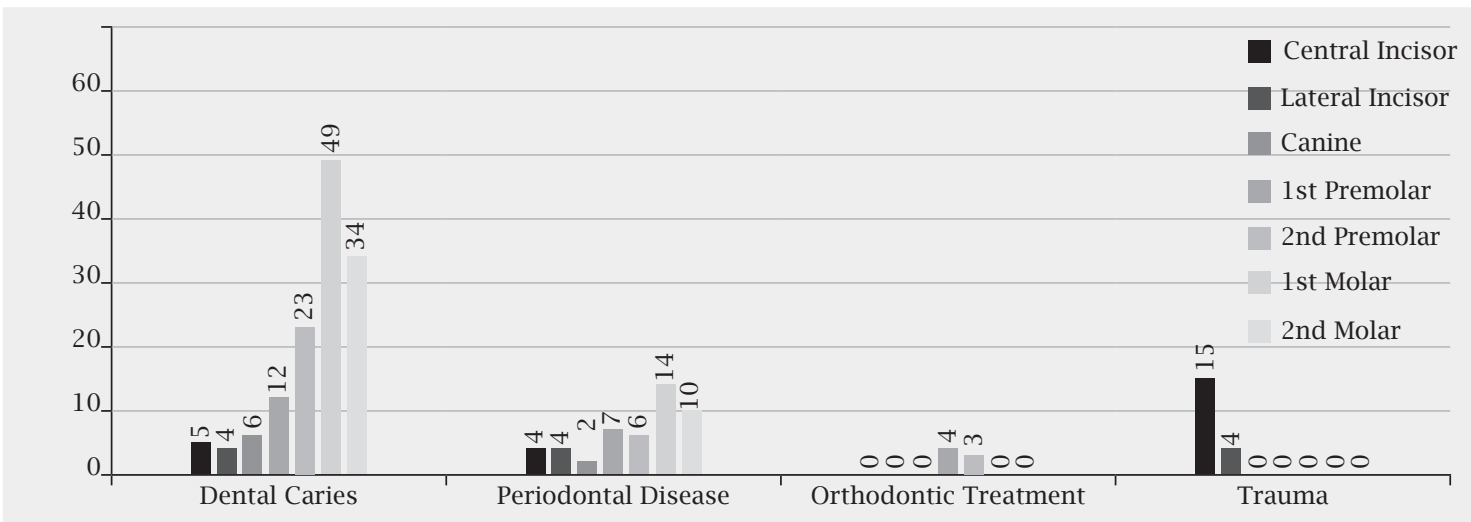

Figure 1: Pattern of tooth loss with reasons of loss in maxillary segment.

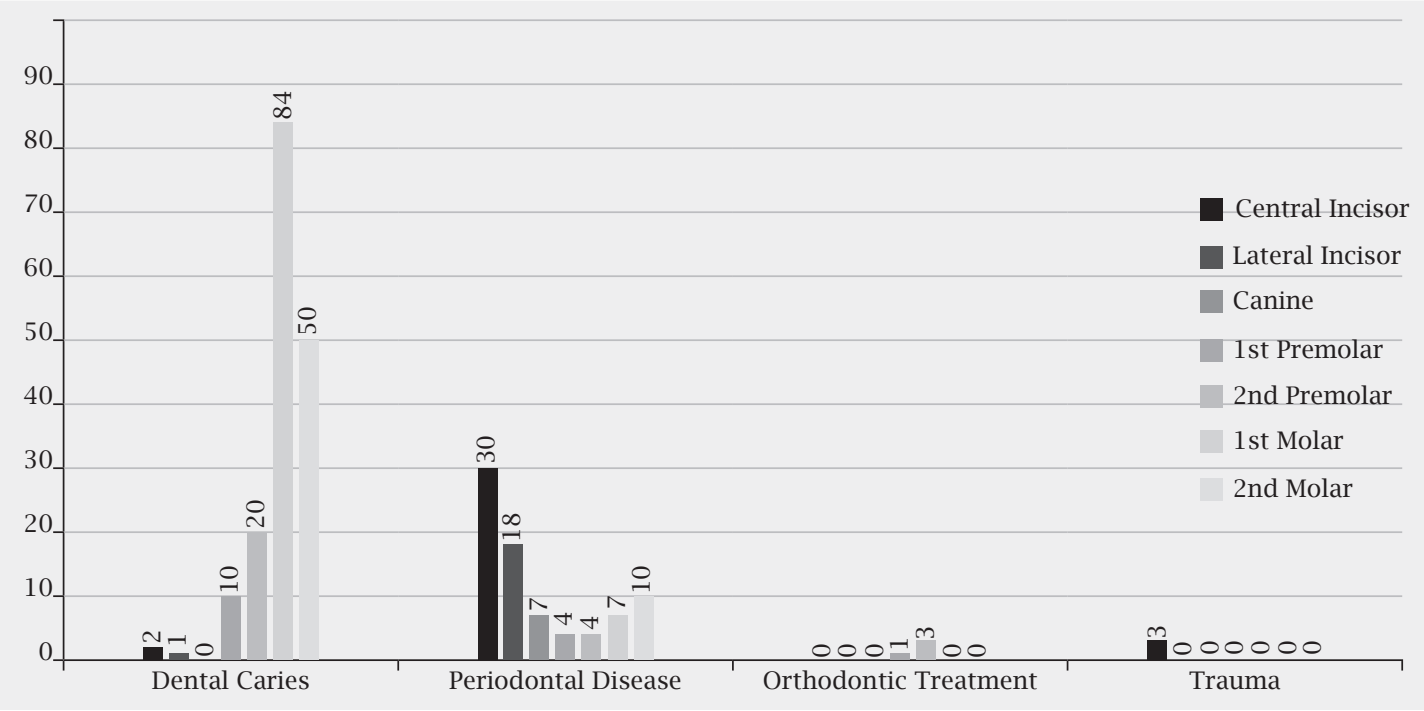

Figure 2: Pattern of tooth loss with reasons of loss in mandibular arch.

Table 2: Distribution of study participants according to reasons for missing teeth and for not saving teeth.

\section{Reasons for missing teeth $\quad$ Study participants n (\%)}

\begin{tabular}{|c|c|}
\hline Dental caries & $120(78.9)$ \\
\hline Periodontal disease & $27(17.8)$ \\
\hline Trauma & $15(9.9)$ \\
\hline Orthodontic treatment & $3(2)$ \\
\hline Ignorance & $23(15.1)$ \\
\hline Reasons for not saving teeth & $\mathbf{n}(\mathbf{\%})$ \\
\hline No facility & $24(15.8)$ \\
\hline No time & $6(3.9)$ \\
\hline Other treatment & $3(2)$ \\
\hline Cannot be saved & $99(65.1)$ \\
\hline
\end{tabular}

numbers of mandibular teeth (80) were lost than maxillary teeth (47) due to periodontal disease. Reasons of tooth loss due to trauma was found only in anterior teeth in both the arches (Figure 1 and 2). Majority of the study participants had tooth loss due to dental caries (78.9\%) followed by periodontal disease (17.8\%, Table 2). Major reasons for not saving the tooth were "it could not be saved" (65.1\%) followed by "no facility" (15.8\%, Table 2).

\section{DISCUSSION}

Numerous studies have been conducted in various countries to assess the reasons for tooth loss. However, little data exists in context of Nepal. So, the present study was done to assess the reasons and patterns of tooth loss among patients attending a dental hospital of Kathmandu, Nepal.

The current study showed prevalence of tooth loss in the present study to be $38 \%$ which was higher than study by Narayan et al. ${ }^{13}$ in which the prevalence was $31.7 \%$. However, it was found to be lower than the study by George et al. ${ }^{6}$ who found the prevalence as $45.5 \%$ in their study. This could be due to variations in the sample size and study locations. Mean tooth loss per person in the present study was found to be 2.7 which is similar to a study conducted in Chennai ${ }^{6}$ but higher than a study conducted in Bangalore. ${ }^{14}$

In present study, tooth loss decreased as education increased. Similar results was seen in the study conducted by Bharateesh et al. ${ }^{15}$ This might be because people with higher education are more aware and prefer conservative dental treatment for retaining their teeth rather than extraction. 
Regarding the pattern of tooth loss, the present study suggests that more number of tooth loss was found in mandibular arch than maxillary arch and in left side than in right side similar to a study by Anand et al. ${ }^{16}$

The current study suggests the main cause of tooth loss among the study participants to be dental caries followed by periodontal disease. This finding is in line with the studies done by Anand et al., ${ }^{17}$ Montandon et al., ${ }^{18}$ Jafarian et al., ${ }^{19}$ and Kashif et al. ${ }^{20}$ In the current study, molars accounted for majority of tooth loss due to dental caries similar to a study in Nepal. ${ }^{3}$ This could be attributed to the fact that molars erupt early and have unique occlusal morphology that predispose them to dental decay. Our study showed that anterior teeth were extracted mostly due to periodontal disease. This finding is consistent with another study. ${ }^{21}$ The reason for not saving the tooth in the current study was found to be "it could not be saved". This finding was in contrast to the study by Bharateesh et al. ${ }^{15}$ who found the main reason to be ignorance. This could be because of the cultural differences among different groups of people in different study sites.
The current study cannot be generalised to the Nepalese population as it is done in a single dental hospital. So further research with larger sample size in multiple hospital settings for longer duration could be done for the generalisability of the results.

\section{CONCLUSION}

The results of this study showed that dental caries is still the major cause of tooth loss followed by periodontal disease. This suggests the need to improve oral health care and knowledge through preventive and curative public health measures at the school and community level.

\section{ACKNOWLEDGEMENTS}

We would like to thank Dr. Sunita Khanal, Department of Community Dentistry, Kantipur Dental College, Dr. Rosina Bhattarai, Department of Community Dentistry, College of Medical Sciences, Bharatpur and all the staffs of Department of Oral Medicine and Radiology, Kantipur Dental College for their guidance and support.

Conflict of Interest: None.

\section{REFERENCES}

1. $\quad$ Peter S. Essentials of Public Health Dentistry (Community Dentistry). Fifth ed. New Delhi: Arya Medi Publishing House Pvt. Ltd.; 2015.

2. Da'ameh D. Reasons for permanent tooth extraction in the North of Afghanistan. J Dent. 2006;34(1):48-51.

3. Dixit LP, Gurung CK, Gurung N, Joshi N. Reasons underlying the extraction of permanent teeth in patients attending Peoples Dental College and Hospital. Nepal Med Coll J. 2010;12(4):203-6.

4. Jafarian M, Etebarian A. Reasons for extraction of permanent teeth in general dental practices in Tehran, Iran. Med Princ Pract. 2013;22(3):239-44.

5. Upadhyaya C, Humagain M. The pattern of tooth loss due to dental caries and periodontal disease among patients attending dental department (OPD), Dhulikhel Hospital, Kathmandu University Teaching Hospital (KUTH), Nepal. Kathmandu Univ Med J 2009;7(25):59-62.

6. George B, John J, Saravanan S, Indiran MA. Prevalence of permanent tooth loss among children and adults in a suburban area of Chennai. Indian J Dent Res. 2011;22(2):364.

7. Barbato PR, Nagano HCM, Zanchet FN, Boing AF, Peres MA. Tooth loss and associated socioeconomic, demographic, and dental-care factors in Brazilian adults: an analysis of the Brazilian Oral Health Survey, 2002-2003. Cad Saude Publica. 2007;23(8):1803-14.

8. McCaul L, Jenkins W, Kay E. Public dental health: The reasons for extraction of permanent teeth in Scotland: a 15-year follow-up study. Br Dent J. 2001;190(12):658-62.

9. Aida J, Ando Y, Akhter R, Aoyama H, Masui M, Morita M. Reasons for permanent tooth extractions in Japan. J Epidemiol. 2006;16(5):214-9.

10. Kressin N, Boehmer U, Nunn M, Spiro III A. Increased preventive practices lead to greater tooth retention. J Dent Res. 2003;82(3):223-7.

11. Sanya BO, Ng'ang'a PM, Ng'ang'a RN. Causes and pattern of missing permanent teeth among Kenyans. East Afr Med J. 2004;81(6):322-5.

12. Aderinokun G, Dosumu O. Causes of tooth mortality in a Nigerian urban centre. Odonto Stomatol Trop. 1997;10(11):12-4.

13. Narayan M, Rao GN, Srinivas S. Prevalence of tooth loss in the young population attending the out patient department of Sardar Patel Post Graduate Institute of Dental and Medical Sciences, Lucknow-A hospital based pilot study. J Indian Assoc Public Health Dent. 2008;6(12):52-5.

14. Rajesh S, Ali KSH. Reasons for extraction of permanent teeth among age group of 15-50 years in Bangalore City. J Indian Assoc Public Health Dent. 2011;9(18):599-606.

15. Bharateesh J, Mythri H, Bennadi D. Prevalence and reasons for tooth mortality-A hospital based study. J Indian Assoc Public Health Dent. 2011;9(18):380-3.

16. Anand PS, Kuriakose S. Causes and patterns of loss of permanent teeth among patients attending a dental teaching institution in south India. J Contemp Dent Pract. 2009;10(5):057-64.

17. Anand P, Kamath K, Nair B. Trends in extraction of permanent teeth in private dental practices in Kerala state, India. J Contemp Dent Pract. 2010;11(3):41-8.

18. Montandon AAB, Zuza EP, de Toledo BEC. Prevalence and reasons for tooth loss in a sample from a dental clinic in Brazil. Int J Dent. 2012;Article ID 719750.

19. Jafarian M, Etebarian A. Reasons for extraction of permanent teeth in general dental practices in Tehran, Iran. Med Princ Pract. 2013;22(3):239-44.

20. Kashif M, Mehmood K, Ayub T, Aslam M. Reasons and patterns of tooth extraction in a tertiary care hospital-A cross sectional prospective survey. J Liaquat Uni Med Health Sci. 2014;13(3):125-9.

21. Yasser F, Ghumman N, Atif S. Frequency and reasons for tooth extraction at institute of dentistry, CMH Lahore Medical College. Pak J Surg. 2016;32(3):185-8. 